\title{
MicroRNA-200c and microRNA- 141 are regulated by a FOXP3-KAT2B axis and associated with tumor metastasis in breast cancer
}

\author{
Guangxin Zhang ${ }^{1,2}$, Wei Zhang ${ }^{3}$, Bingjin Li ${ }^{1}$, Erica Stringer-Reasor ${ }^{4}$, Chengjing Chu ${ }^{5}$, Liyan Sun ${ }^{3}$, Sejong Bae ${ }^{6}$, \\ Dongquan Chen ${ }^{6}$, Shi Wei ${ }^{7}$, Kenneth Jiao ${ }^{8}$, Wei-Hsiung Yang ${ }^{9}$, Ranji Cui ${ }^{1 *}$, Runhua Liu ${ }^{2,8^{*}}$ and Lizhong Wang ${ }^{2,8^{*}}$ (D)
}

\begin{abstract}
Background: Members of the microRNA (miR)-200 family, which are involved in tumor metastasis, have potential as cancer biomarkers, but their regulatory mechanisms remain elusive.

Methods: We investigated FOXP3-inducible breast cancer cells, Foxp3 heterozygous Scurfy mutant (Foxp $3^{\text {sf } /+}$ ) female mice, and patients with breast cancer for characterization of the formation and regulation of the miR-200 family in breast cancer cells and circulation. Participants (259), including patients with breast cancer or benign breast tumors, members of breast cancer families, and healthy controls, were assessed for tumor and circulating levels of the miR-200 family.

Results: First, we identified a FOXP3-KAT2B-miR-200c/141 axis in breast cancer cells. Second, aging Foxp $3^{5 f / 4}$ female mice developed spontaneous breast cancers and lung metastases. Levels of miR-200c and miR-141 were lower in Foxp $3^{\text {sf/ }}$ tumor cells than in normal breast epithelial cells, but plasma levels of miR-200c and miR-141 in the Foxp $3^{\text {sf/ }}$ mice increased during tumor progression and metastasis. Third, in patients with breast cancer, the levels of miR-200c and 141 were lower in FOXP3 ${ }^{\text {low }}$ relative to those with FOXP3 ${ }^{\text {high }}$ breast cancer cells, especially in late-stage and metastatic cancer cells. The levels of miR-200c and miR-141 were higher in plasma from patients with metastatic breast cancer than in plasma from those with localized breast cancer, with benign breast tumors, with a family history of breast cancer, or from healthy controls. Finally, in Foxp $3^{\mathrm{sf} / \mathrm{t}}$ mice, plasma miR-200c and miR-141 appeared to be released from tumor cells.

Conclusions: miR-200c and miR-141 are regulated by a FOXP3-KAT2B axis in breast cancer cells, and circulating levels of miR-200c and miR-141 are potential biomarkers for early detection of breast cancer metastases.
\end{abstract}

Keywords: microRNA, FOXP3, Breast cancer, Tumor metastasis, Circulation, Exosome

\section{Background}

In the USA, an estimated 231,840 women were diagnosed with breast cancer in 2015 , and there were approximately 40,290 deaths [1]. Within 3 years of diagnosis, $10-15 \%$ of breast cancers develop distant metastases [2]. Therefore, predictive tests are needed to

\footnotetext{
* Correspondence: cuiranji@jlu.edu.cn; runhua@uab.edu; Iwang12@uab.edu 'Provincial Key Laboratory on Molecular and Chemical Genetic, The Second Hospital of Jilin University, Changchun 130041, People's Republic of China 2Department of Genetics, University of Alabama at Birmingham, Birmingham, AL 35294, USA

Full list of author information is available at the end of the article
}

identify individuals who are at high risk of metastases. To reduce breast cancer metastasis-related morbidity and mortality, the ideal biomarker should be accessible for non-invasive sampling and sensitive enough to detect early onset of tumor metastasis. To date, only a few markers, such as estrogen receptor (ER), progesterone receptor (PR), and human epidermal growth factor receptor 2 (HER2), have been identified as predictors of clinical responses to breast cancer treatments. None of these markers, however, evaluate tumor invasion or provide early detection of tumor metastasis. 
MicroRNAs (miRs) are small non-coding RNA molecules that regulate gene expression. In breast cancers, aberrant miR expression influences tumor development and progression [3]. Some miRs are upregulated in breast cancer, whereas others are downregulated, suggesting that miRs may have tumor-specific profiles. MiRs are remarkably stable in the circulation, and in formalin-fixed, paraffin-embedded tissues [4]. Thus, they have potential to serve as breast cancer biomarkers. Circulating miRs, which are present in breast cancer patients, have potential as biomarkers that can be obtained by a minimally invasive procedure [5-10]. Members of the human and mouse miR-200 family (miR-200 s), including two clusters (cluster 1: miR-200b, 200a, and 429, on chromosome 1, and cluster 2: miR-200c and miR-141, on chromosome 12), inhibit the epithelial-mesenchymal transition (EMT) [11, 12] but promote the mesenchymal-epithelial transition (MET) $[13,14]$, thereby regulating tumor metastasis by a reversible EMT-MET transition. In cancer cells, miR-200 s induce epithelial differentiation by suppressing ZEB1/2 and subsequently increasing E-cadherin expression [11, 12]. Apart from the miR-200-ZEB1/2-E-cadherin axis, miR-200 s inhibit Wnt through CTNNB1, NOTCH through JAG1, and SNAIL through SNAI2, and other direct targets, FN1, MSN, NTRK2, LEPR, and ARHGAP19, all of which are necessary for tumor metastasis [15-17]. Decreased levels of miR-200 s in tumor cells have been implicated in the invasion and metastasis of breast cancer [11, 12, 18], but, in preclinical models, restoration of miR-200c reduced metastases [19], suggesting that the miR-200 s function as tumor suppressors. Conversely, some studies suggest that, in cancer cells, miR-200 s promote tumor metastasis through promotion of tumor colonization at metastatic sites [13, 14]. In murine cancers and human xenograft models, miR200-expressing tumor cells and extracellular vesicles from these tumor cells promote breast cancer metastasis and confer the capacity for these cells to colonize distant tissues in an miR-200-dependent manner [20]. Further, high levels of circulating miR-200 $\mathrm{s}$ in breast cancer patients are associated with increased numbers of circulating tumor cells (CTCs) [21], which are a predictor of metastasis up to 2 years prior to clinical diagnosis [22] and of shorter brainmetastasis-free survival [23]. Thus, circulating miR-200 s are promising biomarkers for breast cancer metastasis. However, the cellular origin, mechanism of release, and function of circulating miR-200 s during tumor progression and metastasis remain elusive.

FOXP3 functions as the master regulator in the development and function of regulatory $\mathrm{T}$ cells [24]. Our group found that FOXP3 is also a breast epithelial cellintrinsic tumor suppressor [25-27]. Unlike normal breast epithelial cells, $60-80 \%$ of human breast cancer cells lack nuclear expression of FOXP3 [25, 26, 28, 29]. Aging female mice with a heterozygous Scurfy (sf) mutation of Foxp3 $\left(F o x p 3^{\text {sf } /+}\right)$, which causes a loss of Foxp3 expression, frequently develop spontaneous breast cancers $\left(\mathrm{ER}^{+}, 14 / 18 ; \mathrm{PR}^{+}, 12 / 18 ; \mathrm{ErbB}^{+}, 18 / 18\right)$ after 1 year of age, and $40 \%$ of these mice with primary breast tumors also develop lung metastases [26]. Thus, this mouse model is appropriate for finding and validating breast cancer biomarkers and for evaluating their cellular origin, identifying their mechanism of release, and assessing the function of circulating miRs during tumor progression and metastasis. In the present work, we explored the relevance of FOXP3-mediated transcriptional regulation of miR-200 $\mathrm{s}$ in breast cancer cells in mice and humans. We also investigated the cellular origin, mechanism of release, and function of plasma miR-200 s in breast cancer cells and in mouse models.

\section{Methods}

\section{Cell lines, antibodies, and reagents}

Breast cancer cell lines MCF7, T47D, BT474, and MDAMB-468 were obtained from the American Type Culture Collection (Manassas, VA, USA). Cell lines were authenticated by examination of morphology and growth characteristics and were confirmed to be mycoplasma-free. A short tandem-repeat analysis for DNA fingerprinting was also used to verify the human cell lines. Green fluorescent protein (GFP) and FOXP3/GFP-Tet-off MCF7 cells were established and maintained in doxycycline (Dox, $10 \mu \mathrm{g} / \mathrm{ml}$ ) as described previously $[25,30]$. Specific primary antibodies were used to detect the following proteins: FOXP3 (ab450, 1:2,000, ABCAM, Cambridge, MA, USA), PCAF (KAT2B) (C14G9, 1:1,000, Cell Signaling Technology, Danvers, MA, USA), and PITX2 (ab98297, 1:2,000, ABCAM). The pEF1FOXP3-V5 vector [31] or empty pEF1 vector was transfected into cells using FuGENE6 (Promega, Madison, WI, USA). KAT2B and PITX2 small interfering RNAs (siRNAs) are listed in Additional file 1: Table S1.

\section{Experimental animals}

Mice with an $s f$ mutation in the Foxp3 locus were purchased from the Jackson Laboratory (Bar Harbor, ME, USA). The $s f$ mouse has a spontaneous Foxp 3 frameshift mutation, resulting in loss of FOXP3 function. Homozygous or hemizygous $s f$ mice generally die within 2 weeks after birth, but heterozygous scurfy female mice have a normal life span. In our previous studies [26], we established the Foxp $3^{\text {sf/+ }}$ mouse model, which was used here for monitoring the mechanisms involved in the progression and metastasis of breast cancers. These mice have a BALB/c background. F1 Foxp $3^{\text {sf/+ }}$ female mice of appropriate genotypes were used. All animal experiments were conducted in accordance with accepted standards of animal care and approved by the Institutional Animal Care and Use Committee of University of Alabama at Birmingham (UAB). 


\section{Human subjects}

The plasma and blood samples from 259 human subjects, including 114 patients with breast cancer, 30 patients with benign breast tumors, 21 women with a family history of breast cancer, and 94 healthy women were obtained from the UAB Tissue Collection and Banking Facility (Table 1). Patient demographics and tumor clinicopathologic details are shown in Table 1 . The pathologic stage of breast cancer at the time of diagnosis was determined by use of the tumor-node-metastasis (TNM) system. Tumor grading was that corresponding to grade 1 (well-differentiated), grade 2 (moderately differentiated), or grade 3 (poorly differentiated) tumors. All patients with distant metastasis were diagnosed by follow up after surgery. Normal female controls (identified by a routine health visit) were matched with patients for age, race, reproductive status, region of residence, and duration of plasma storage. Only plasma obtained prior to any clinical treatment was used.

Two independent cohorts of human subjects were divided for assessment and validation of the miR-200 family as potential biomarkers. For the first cohort, we obtained plasma from 134 human subjects, including 33 patients with invasive breast cancer (19 with pT1-4, 11 with N1-3, and 3 with M1), 6 patients with non-invasive breast cancer (ductal carcinoma in situ (DCIS), pTis), 30 patients with benign breast tumors, 21 women with a family history of breast cancer, and 44 healthy female controls. In the second cohort, we obtained the plasma from 125 human subjects in a separate Caucasian population, including 50 patients with local breast cancer (42 with pT1-2N0M0 and 8 with pT3-4NOM0) and 25 patients with metastatic breast cancer (15 with only lymph node involvement (N1-3) after surgery, and 10 with distant metastatic disease (i.e., lungs, liver, bones) (M1) diagnosed after surgery), and 50 normal healthy women. In addition, we obtained blood cells from 30 of $125 \mathrm{hu}$ man subjects, including 10 patients with local breast cancer (pT1-4N0M0) and 10 patients with metastatic breast cancer (distant metastasis after surgery), and 50 healthy female controls. The ER/PR/HER2 status in patients with breast cancer was: ER, 46 positive and 29 negative patients; PR, 41 positive and 34 negative patients; HER2, 28 positive and 47 negative patients. Tumor grades for patients in breast cancer were welldifferentiated (4 patients), moderately differentiated (38 patients), and poorly differentiated (33 patients). Tumor types in patients with breast cancer were invasive ductal carcinoma (58 patients), invasive lobular carcinoma (9 patients), and unclassified type (8 patients).

\section{Sample collection}

Blood from mice and humans was collected in EDTA tubes (BD Biosciences). All samples for isolation of plasma
Table 1 Characteristics of human subjects

\begin{tabular}{|c|c|c|c|c|c|c|}
\hline \multirow[b]{2}{*}{ Categories } & \multicolumn{4}{|c|}{ First cohort } & \multicolumn{2}{|c|}{ Second cohort } \\
\hline & $\overline{\mathrm{BC}^{\mathrm{a}}}$ & Benign $^{\mathrm{b}}$ & Family $^{c}$ & $\overline{\text { Control }^{d}}$ & $\overline{\mathrm{BC}^{\mathrm{a}}}$ & Control $^{d}$ \\
\hline Total number & 39 & 30 & 21 & 44 & 75 & 50 \\
\hline $\begin{array}{l}\text { Recruiting } \\
\text { time, years }\end{array}$ & $\begin{array}{l}2004- \\
2014\end{array}$ & $\begin{array}{l}2004- \\
2014\end{array}$ & $\begin{array}{l}2004- \\
2014\end{array}$ & $\begin{array}{l}2004- \\
2014\end{array}$ & $\begin{array}{l}2004- \\
2014\end{array}$ & $\begin{array}{l}2004- \\
2014\end{array}$ \\
\hline $\begin{array}{l}\text { Median age } \\
\text { (range), years }\end{array}$ & $\begin{array}{l}51 \\
(30-73)\end{array}$ & $\begin{array}{l}51 \\
(40-63)\end{array}$ & $\begin{array}{l}47 \\
(33-71)\end{array}$ & $\begin{array}{l}50 \\
(36-70)\end{array}$ & $\begin{array}{l}52 \\
(32-75)\end{array}$ & $\begin{array}{l}52 \\
(37-71)\end{array}$ \\
\hline \multicolumn{7}{|l|}{ Race } \\
\hline Caucasian & 26 & 28 & 20 & 36 & 75 & 50 \\
\hline African-American & 11 & 1 & 1 & 7 & 0 & 0 \\
\hline Other & 2 & 1 & 0 & 1 & 0 & 0 \\
\hline \multicolumn{7}{|l|}{ ER status } \\
\hline Positive & 26 & & & & 46 & \\
\hline Negative & 4 & & & & 29 & \\
\hline Unknown & 9 & & & & 0 & \\
\hline \multicolumn{7}{|l|}{ PR status } \\
\hline Positive & 24 & & & & 41 & \\
\hline Negative & 5 & & & & 34 & \\
\hline Unknown & 10 & & & & 0 & \\
\hline \multicolumn{7}{|l|}{ HER2 status } \\
\hline Positive & 6 & & & & 28 & \\
\hline Negative & 25 & & & & 47 & \\
\hline Unknown & 8 & & & & 0 & \\
\hline \multicolumn{7}{|c|}{ Histological subtype } \\
\hline Ductal & 30 & & & & 58 & \\
\hline Lobular & 2 & & & & 9 & \\
\hline Both & 2 & & & & 0 & \\
\hline Unclassified & 5 & & & & 8 & \\
\hline \multicolumn{7}{|l|}{ Tumor grade } \\
\hline Well & 2 & & & & 4 & \\
\hline Moderate & 13 & & & & 38 & \\
\hline Poor & 17 & & & & 33 & \\
\hline Unknown & 7 & & & & 0 & \\
\hline \multicolumn{7}{|l|}{ Tumor stage } \\
\hline \multicolumn{7}{|l|}{ Localized } \\
\hline DCIS (pTis) & 6 & & & & 0 & \\
\hline $\begin{array}{l}\text { Early } \\
\text { (pT1-2NOMO) }\end{array}$ & 15 & & & & 42 & \\
\hline $\begin{array}{l}\text { Advanced } \\
\text { (pT3-4NOMO) }\end{array}$ & 4 & & & & 8 & \\
\hline \multicolumn{7}{|l|}{ Metastatic } \\
\hline $\begin{array}{l}\text { Regional } \\
\text { (pT1-4 N1-3 M0) }\end{array}$ & 11 & & & & 15 & \\
\hline $\begin{array}{l}\text { Distant } \\
\text { (pT1-4 M1) }\end{array}$ & 3 & & & & 10 & \\
\hline
\end{tabular}

ER estrogen receptor, $P R$ progesterone receptor, HER2 human epidermal growth factor receptor, $D C I S$ ductal carcinoma in situ, $T$ tumor, $N$ node, $M$

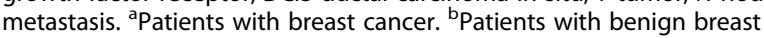
tumor. 'Normal healthy women with family history of breast cancer. ${ }^{\mathrm{d} N o r m a l}$ healthy women without family history of breast cancer 
and blood cells were centrifugally processed within 4 hours of collection. To avoid the release of miRs from blood cells during the coagulation process [32], miRs in plasma were assessed. Cell-free plasma and blood cells were stored at $-80{ }^{\circ} \mathrm{C}$ until analysis.

\section{Laser capture microdissection}

Laser capture microdissection was performed as described previously [33]. For analysis of gene expression, cells $\left(5 \times 10^{3}\right)$ were microdissected from target tissues.

\section{Exosome isolation}

Cell culture medium and plasma was centrifuged at $300 \times \mathrm{g}$ for 10 minutes to clear cells and large debris. The supernatant was centrifuged at $2000 \times \mathrm{g}$ for $20 \mathrm{mi}-$ nutes and then at $10,000 \times \mathrm{g}$ for 30 minutes to remove residual membranous debris. The remaining supernatant was subjected to ultracentrifugation at $100,000 \times \mathrm{g}$ for 70-120 minutes to pellet the exosomes [34, 35].

\section{RNA isolation}

For isolation of RNA, $200 \mu \mathrm{l}$ of plasma or $2 \mu \mathrm{g}$ of purified exosomes in $200 \mu \mathrm{l}$ PBS were thawed on ice and lysed with an equal volume of $2 x$ Denaturing Solution (Life Technologies). To normalize sample-to-sample variation in plasma or exosomal RNA isolation, $25 \mathrm{fmol}$ of synthetic Caenorhabditis elegans miR cel-miR-39 (QIAGEN, Valencia, CA, USA) was added to each denatured sample [4]. Total RNA was extracted using miRNeasy Serum/Plasma Kits (QIAGEN). RNA was isolated from blood cells and cultured cells by the Trizol (Life Technologies) method.

\section{TaqMan miR assay}

Levels of mature miR-200 s in tumor cells, cultured cells, and blood cells were assessed by use of TaqMan MicroRNA Assays (Life Technologies) as described previously $[31,33]$. The average relative amounts were determined using the comparative method $\left(2^{-\Delta \mathrm{Ct}}\right)$ against endogenous RNU6B (for humans) or snoRNA202 (for mice) controls.

\section{Nest-quantitative PCR (qPCR) analysis}

Due to the low amounts of mature miR-200 s in plasma and exosomes, nest-qPCR analyses were performed to measure mature miR-200 s. Briefly, $5 \mu \mathrm{l}$ of RNA in $20 \mu \mathrm{l}$ reactions was reverse-transcribed using the miScript II RT Kit (QIAGEN). cDNA $(2 \mu \mathrm{l})$ was added to $20-\mu \mathrm{l}$ reactions for preamplification PCR as described previously [4]. Then, 2- $\mu$ l portions of the PCR products were used as templates for real-time PCR with a LightCycler 480 Real Time PCR System (Roche Applied Sciences, Indianapolis, IN, USA) with miScript SYBR Green PCR kits (QIAGEN) at $95{ }^{\circ} \mathrm{C}$ for 2 minutes, followed by 40 cycles of $95^{\circ} \mathrm{C}$ for $15 \mathrm{sec}$ and $60^{\circ} \mathrm{C}$ for 1 minute. The relative quantities of miRs in plasma were determined with an adjusted cycle threshold $(\mathrm{aCt})$ value against the spiked-in control cel-miR-39 (QIAGEN) as described previously [21]. The relative quantities in exosomes were determined by the comparative method $\left(2^{-\Delta \mathrm{Ct}}\right)$ against the spiked-in control cel-miR-39 (QIAGEN). The nestqPCR primers are listed in Additional file 1: Table S1.

\section{Western blots and quantitative chromatin immunoprecipitation (ChIP) assays}

Western blotting was performed as previously described $[25,26,31]$. For nuclear proteins, the cells were first incubated in buffer A (10 mmol/L HEPES (pH 7.8), $10 \mathrm{mmol} / \mathrm{L}$ $\mathrm{KCl}, 2 \mathrm{mmol} / \mathrm{L} \mathrm{MgCl}_{2}, 0.1 \mathrm{mmol} / \mathrm{L}$ EDTA, $1 \% \mathrm{NP} 40$, and protease inhibitors), and the pellet was suspended in buffer B (50 mmol/L HEPES (pH 7.8), $300 \mathrm{mmol} / \mathrm{L} \mathrm{NaCl}, 50$ $\mathrm{mmol} / \mathrm{L} \mathrm{KCl}, 0.1 \mathrm{mmol} / \mathrm{L}$ EDTA, $10 \%$ (v/v) glycerol, and protease inhibitors). ChIP assays were accomplished according to our previous reports [25, 26, 31]. The FOXP3expressing tet-off cells were sonicated and fixed with $1 \%$ paraformaldehyde. Anti-FOXP3 and anti-IgG (Santa Cruz Biotechnology) antibodies were used to pull down chromatin associated with FOXP3. The amounts of specific DNA fragments were quantitated by real-time PCR and normalized against the genomic DNA preparations from the same cells. The ChIP qPCR primers are listed in Additional file 1: Table S1.

\section{Statistical analyses}

Continuous variables were summarized using sample size, mean, standard deviation (SD), median, and minimum and maximum values. Categorical data were summarized using frequency and proportion. The distribution of data for each group was evaluated using the one-sample KolmogorovSmirnov test. In samples with normal distributions, the means of the variables were compared between two groups using the two-tailed $t$ test. In samples with non-normal distributions, the medians of the variable were compared between two groups using the Mann-Whitney test. One-way and two-way analysis of variance (ANOVA) was used to test for overall differences, followed by the protected least significant difference test for differences between groups. The receiver operating characteristic (ROC) curve was used to assess the diagnostic accuracy of each miR, and the sensitivity and specificity of the optimum cutoff point was defined as those values that maximized the area under the curve (AUC). All data were entered into an Access database using Excel 2013 and analyzed using SPSS (version 20; IBM, Armonk, NY, USA), StatView (version 5.0.1), and SAS (SAS Institute Inc., Cary, NC, USA).

\section{Results}

\section{FOXP3 induces miR-200c and miR-141 in human breast} cancer cells

The FOXP3/GFP-Tet-off MCF-7 cell lines (ER ${ }^{+}, \mathrm{PR}^{+}$, HER2 ${ }^{-}$) were used to express FOXP3 in the absence of Dox 
(Fig. 1a). Levels of miR-200 $\mathrm{s}$ in the FOXP3/GFP-Tet-off MCF-7 cell lines were assessed by use of qPCR at 24 and 48 hours after FOXP3 induction. As shown, miRs-200c and miR-141 at miR-200 cluster 2 (2.0-fold to 3.2-fold miR200c induction; 1.8 -fold to 2.6-fold miR-141 induction), but not miRs-200b, 200a, and 429 at miR-200 cluster 1 , were induced after FOXP3 induction (Fig. 1b). These observations were confirmed with FOXP3-transfected T47D $\left(\mathrm{ER}^{+}\right.$, $\left.\mathrm{PR}^{+}, \mathrm{HER} 2^{-}\right)$, BT474 $\left(\mathrm{ER}^{+}, \mathrm{PR}^{+}, \mathrm{HER} 2^{+}\right)$, and MDA-MB$468\left(\mathrm{ER}^{-}, \mathrm{PR}^{-}, \mathrm{HER} 2^{-}\right)$cells at 48 hours after transfection (1.8-fold to 2.4-fold miR-200c induction, 3.6-fold to 6.7-fold miR-141 induction) (Fig. 1c). Since endogenous FOXP3 is expressed in the normal immortalized human epithelial cell line, MCF10A [31], we knocked down FOXP3 in MCF10A cells by short hairpin RNAs [31] and found that expressions of miR-200c and miR-141 in the cells were decreased after FOXP3 silencing (Additional file 1: Figure S1A-B).

To determine if miR-200 is expressed in human breast cancers, the breast invasive carcinoma $(n=1100)$ expression dataset (RNAseqV2, UNC) from NCI The Cancer Genome Atlas (TCGA) was examined. In total, 542 samples were available for analyses of expression of both miR-200 s and FOXP3. These were divided into two subgroups $\left(F O X P 3^{\text {low }}\right.$ and $\left.F O X P 3^{\text {high }}\right)$ by a medium value of FOXP3 expression in tumor samples. High levels of all miR-200 s were present in FOXP3 ${ }^{\text {high }}$ tumors relative to those in FOXP3 ${ }^{\text {low }}$ tumors (Additional file 1: Figure S2A). Since endogenous expression of FOXP3 in FOXP3 + tumor-infiltrating lymphocytes (TILs) is more than 100-fold higher than in breast epithelial cells [36, 37], FOXP3 $^{+}$TILs may contribute to the expression of FOXP3 in tumors. Most FOXP3 ${ }^{+}$TILs, but not epithelial cells, express CD25 (IL2RA), allowing further stratification of patients by the extent of $C D 25$ expression in tumors (Additional file 1: Figure S2B). To avoid the potential effect of $\mathrm{FOXP3}^{+}$TILs, we selected the $C D 25^{\text {low }}$ tumors, indicative of few $\mathrm{FOXP}^{+}$TILs, to assess the association between expression of FOXP3 and miR-200 $\mathrm{s}$ in the TCGA breast cancers (Additional file 1: Figure S2C). Likewise, high levels of all miR-200 s were validated in $F O X P 3^{\text {high }}$ tumors relative to those in $F O X$ $P 3^{\text {low }}$ tumors (Additional file 1: Figure S2C).

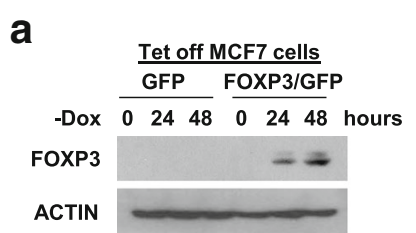

b
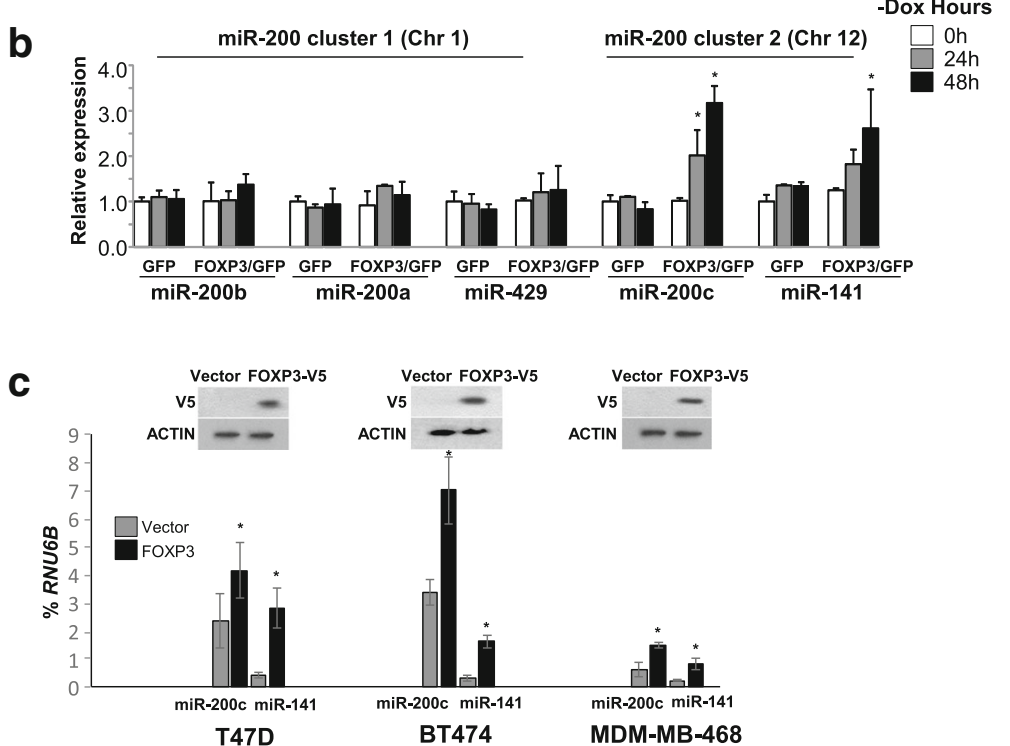

Fig. 1 FOXP3 induces miR-200c and miR-141 in breast cancer cells. a FOXP3 protein expression in green fluorescent protein (GFP) and FOXP3/GFP-Tet-off MCF7 cells was measured by western blotting. -Dox doxycycline removed from the culture medium. b Relative quantification (by quantitative (q)PCR) of miR-200 clusters 1 and 2 in FOXP3/GFP-Tet-off MCF7 cells without Dox at 0, 24, and $48 \mathrm{~h}$. The concentrations of miR-200 s at $0 \mathrm{~h}$ were used as a reference. Chr chromosome. Data are presented as means \pm SD. ${ }^{*} p<0.05$ vs. 0 -h group, analysis of variance followed by the protected least significant difference test for differences between groups. c Quantification of miR-200 s (by qPCR) as a percentage of RUN6B expression in T47D (left), BT474 (middle), and MDA-MB468 (right) cells at $48 \mathrm{~h}$ after transfection. Representative western blot analyses for FOXP3 expression in FOXP3-V5-transfected cells (inset in each panel). Data are presented as the means $\pm \mathrm{SD}$. ${ }^{*} p<0.05$ vs. vector group, two-tailed $t$ test. All experiments were repeated three times 
Molecular mechanism for transcriptional regulation of miR-200c and miR-141 by FOXP3 in breast cancer cells According to our previous ChIP-sequencing data [30], the binding signals of FOXP3 are close $(-3.4 \mathrm{~kb})$ to the locus at non-regulated miR-200 cluster 1 (miR-200a/b/429) but distal $(-20 \mathrm{~kb})$ to the locus at FOXP3-regulated miR-200 cluster 2 (miR-200c/141) in FOXP3/GFP-Tet-off MCF-7 cells (Additional file 1: Figure S3A-B). In the present study, no FOXP3-binding signal was evident at the miR200 cluster 2 locus $(-5 \mathrm{~kb} /+2 \mathrm{~kb})$ as determined by ChIP assays with qPCR analyses (Fig. 2a, b). These data indicate that in MCF-7 cells, miR-200c and miR-141 are regulated indirectly by FOXP3. Furthermore, the literature was reviewed to identify 10 candidates of transcriptional regulators of miR-200c and miR-141: ASCL2 [38], EP300 [39], KAT2B [39], KLF5 [40], MUC1 [41], PITX2 [42], TGF $\beta 1$ [43], TP53 [44], and ZEB1/2 [45]. Expressions of these genes in FOXP3/GFP-Tet-off MCF7 cells were analyzed before and after FOXP3 induction (Fig. 2c) using our previous microarray data with ChIP-sequencing data [30, 31]. To confirm promising candidates, qPCR analyses were performed for mRNA expression of all candidate genes. After FOXP3 induction in FOXP3/GFP-Tet-off MCF7 cells, five candidate genes (KAT2B, KLF5, MUC1, PITX2, and TP53) had a $>1.5$-fold change in gene expression (Fig. 2d), but, in the GFP-Tet-off MCF7 control cells, two of these five candidate genes (KAT2B and PITX2) had no significant change ( $<1.5$-fold, Fig. 2e). The downregulation of KAT2B and PITX2 proteins in response to FOXP3 induction were validated by western blots (Fig. 2f). Thus, in FOXP3-mediated transcriptional regulation of miR-200c and miR-141, KAT2B and PITX2 appeared to be coordinators between FOXP3 and miR-200c and miR-141. To evaluate this possibility, siRNAs were used to knock down KAT2B and PITX2 (Fig. 2g). Of note, miR-200c/141 were reduced after KAT2B or PITX2 knockdown and were then induced by FOXP3 in the PITX2-silenced cells, but no significant changes were evident after FOXP3 induction in the KAT2B-silenced cells (Fig. 2h). The results established that $K A T 2 B$, but not PITX2, is required for FOXP3mediated transcriptional induction of miR-200c and miR141. However, the effect of KAT2B knockdown on the miR-200 cluster 1 miRNAs was not observed in FOXP3/ GFP-Tet-off MCF7 cells (Additional file 1: Figure S4). In addition, we analyzed the FOXP3 ChiP-seq data and identified direct binding signals of FOXP3 in the promoter region of KAT2B in FOXP3/GFP tet-off cells (Additional file 1: Figure $\mathrm{S} 3 \mathrm{C}$ ).

During tumor progression, the amounts of miR-200c and miR-141 are low in primary breast cancer cells but high in circulating plasma

MiR-200c is $100 \%$ conserved between mice and humans, and miR-141 differs by one nucleotide in $5 p$, demonstrating that miRs-200c and miR-141 are highly conserved between mice and humans. To validate our observation in breast cancer cells, we used heterozygous Foxp $3^{\text {sf } /+}$ breast cancer mice to analyze the regulation of mouse miR-200 s during tumor progression. By 1.5 years of age, approximately $40 \%$ of untreated $\mathrm{Foxp} 3^{\mathrm{s} /+}$ female mice develop tumors, and $40 \%$ of those with primary breast tumors experience lung metastases [26]. For each group, 20 mice at 2 years of age were killed, except for those that died or were sacrificed early due to tumor size $\left(>1.0 \mathrm{~cm}^{3}\right)$ or extensive tumor metastasis. Histologic examinations and expression analyses were made for five $F o x p 3^{+/+}$wild-type mice, five Foxp $3^{\text {sf/+ }}$ mice without tumors, five mice with breast tumors only, and five mice with both breast tumors and lung metastases (Fig. 3a). Our previous study demonstrated that FOXP3 protein is reduced in Foxp $3^{\text {sf/+ }}$ breast epithelial cells [26]. By use of laser-capture microdissection, $\mathrm{Foxp}^{+/+}$or Foxp $3^{\text {sf/+ }}$ breast epithelial cells and Foxp $3^{\text {sf/+ }}$ breast cancer cells were obtained from these mice, and the levels of miR$200 \mathrm{~s}$ in the microdissected cells were measured. Levels of miR-200c and miR-141, but not those of miR-200b, miR200a, and miR-429, were reduced in the Foxp $3^{\mathrm{sf} /+}$ breast epithelial cells and tumor cells compared with wild-type breast epithelial cells (Fig. 3b). These data indicate that miR-200c and miR-141 at miR-200 cluster 2 are downstream targets of FOXP3. Furthermore, the miR expression dataset for invasive breast carcinomas, downloaded from the NCI TCGA, was analyzed with tumor stages. In total, 744 patients were available for analyses of expression of miR-200 s. Most miR-200 s were downregulated in latestage primary tumors, but all miR-200 s were downregulated in the primary tumors with metastasis (Fig. 3c). Results of studies of human breast cancers support this observation [5, 21, 46]. In breast cancer cells, however, expression of miR-200 s was not related to ER/PR/HER2 status (Additional file 1: Figure S5A-C).

To determine the levels of miR-200 s in circulation during tumor progression, plasma was collected monthly from Foxp $3^{\mathrm{sf} /+}$ female mice after 1 year of age. Plasma miR-200 s levels were measured at 12 time points by a nest-qPCR analysis. During tumor progression in the Foxp $3^{\text {sf/+ }}$ female mice, there were increased levels of plasma miR-200c and miR-141 at miR-200 cluster 2 (Fig. 3d, the time points of breast tumor development are indicated by vertical arrows) but not at miR-200 cluster 1 (Additional file 1: Figure S6). Furthermore, plasma miR-200c and miR-141 levels were elevated during tumor metastasis (Fig. 3d).

In patients with breast cancer, high levels of plasma miR200c and miR-141 are associated with tumor metastasis

To determine if expression patterns in human breast cancers reflect the data from mice, the levels of plasma $\mathrm{miR}-200 \mathrm{c}$ and miR-141 were examined by nest-qPCR 


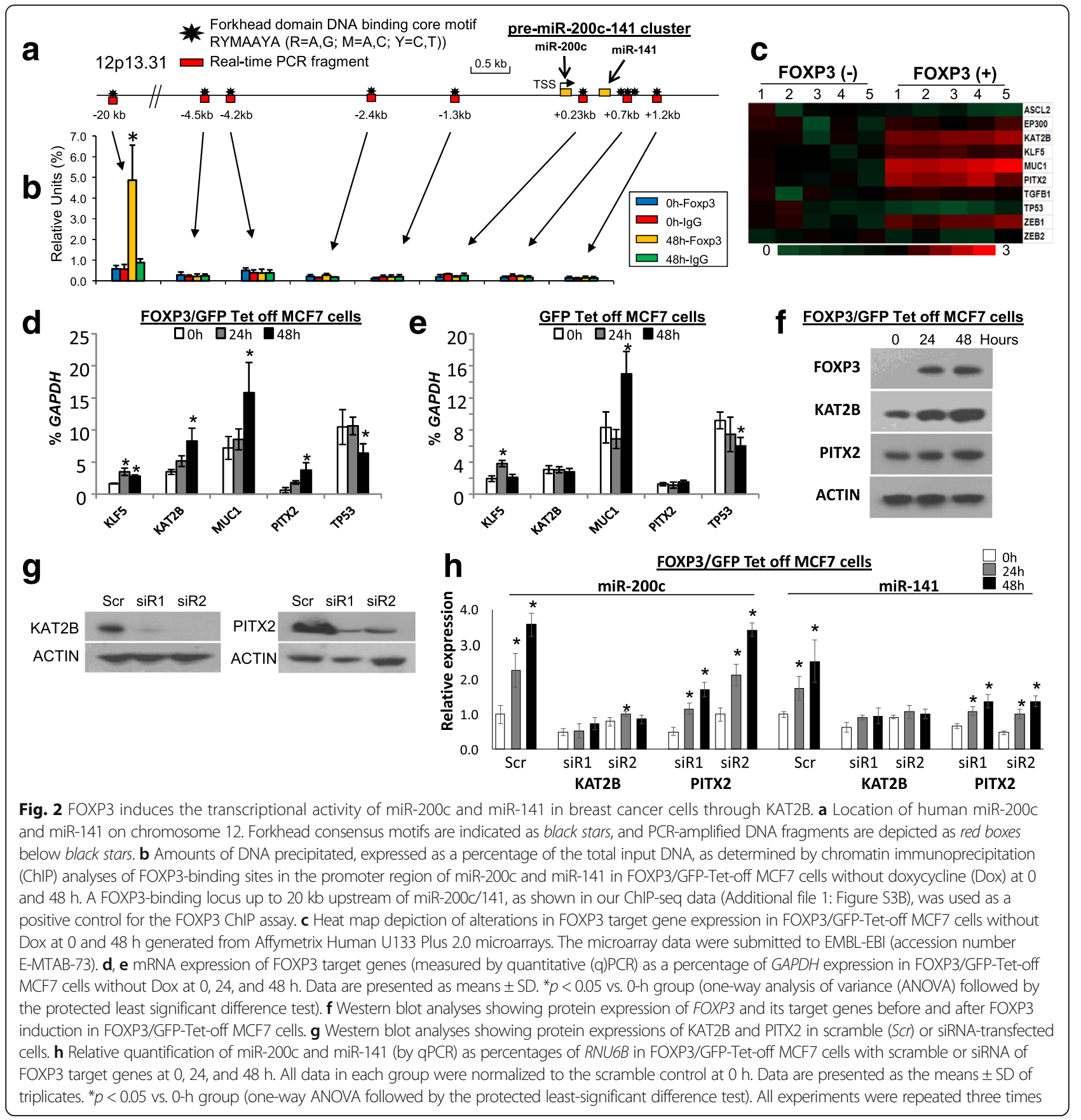

analysis of a breast cancer population. Demographic and other variables, including age, ethnicity, ER/PR/HER2 status, and clinical factors are summarized in Table 1. The plasma levels of miR-200c and miR-141 were determined for 33 patients diagnosed with breast cancer (19 with pT1-4, 11 with N1-3, and 3 with M1), 6 patients with ductal carcinoma in situ (DCIS), 30 patients with benign breast tumors, 21 women with a family history of breast cancer, and 44 healthy female controls. For patients with invasive breast cancer, plasma levels of miR141, but not miR-200c, were higher (a lower adjusted Ct value correlated with a higher level) than levels for the other groups examined (Fig. 4a). There was no significant difference in plasma levels of miR-200c and miR141 between patients with DCIS and healthy controls. There was also no significant difference in plasma miR200c and miR-141 levels between healthy women with and without a family history of breast cancer, suggesting that plasma levels of miR-200c and miR-141 are not hereditary.

For an independent Caucasian cohort, the plasma levels of miR-200c and miR-141 were examined for 50 


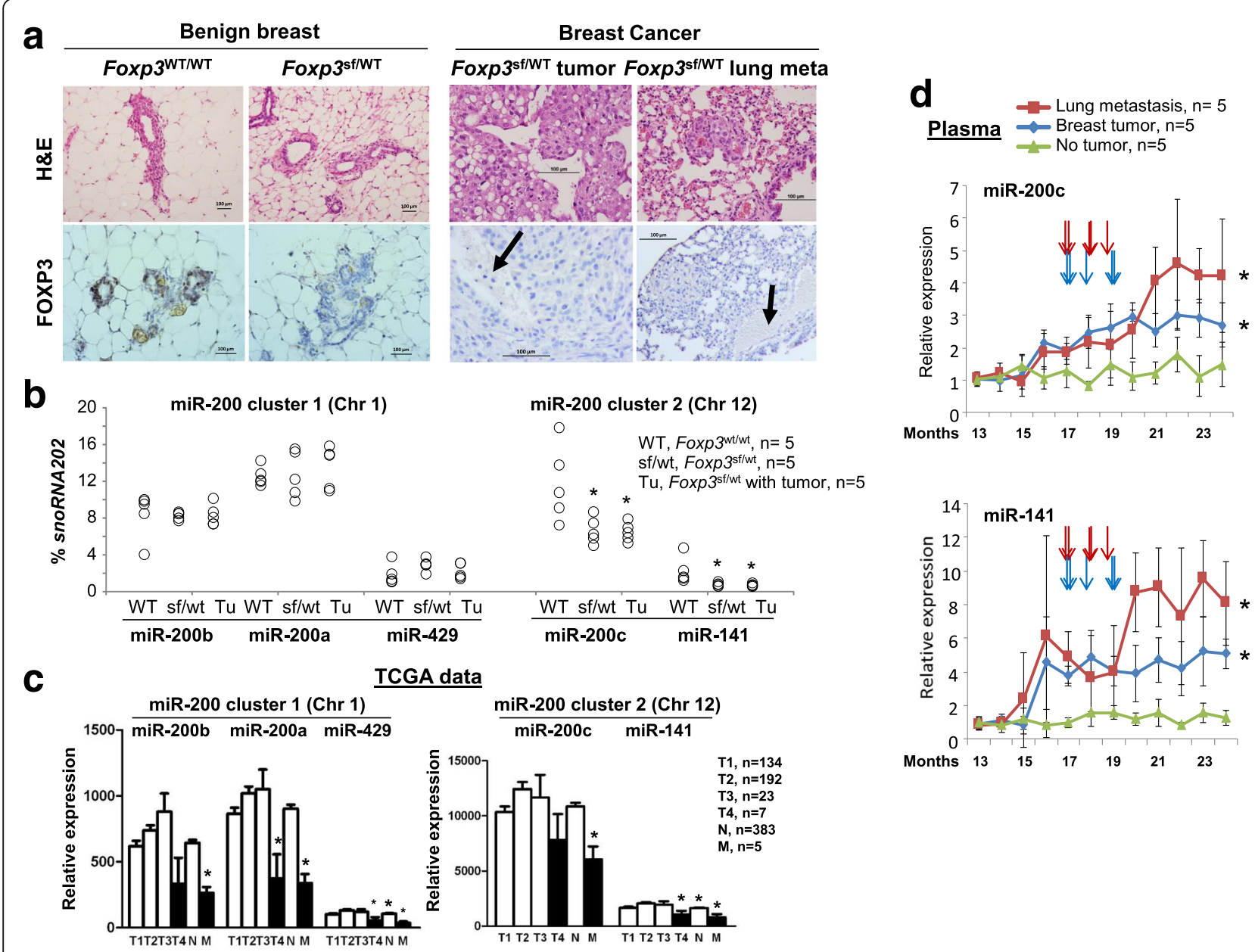

Fig. 3 Changes in miR-200 s in tumor cells and plasma during breast cancer progression. a Representative hematoxylin and eosin (H\&E) and FOXP3 immunohistochemical staining of breast tissues, breast tumors, and lung metastases in mice. Meta metastasis, WT wild-type, Sf scurfy, Tu breast tumor. Black arrows indicate the vasculature. $\mathbf{b}$ Levels of cluster 1 and cluster 2 miR-200 s (measured by quantitative (q)PCR) as percentages of snoRNA202 expression in microdissected breast epithelial cells and tumor cells. ${ }^{*} p<0.05$ vs. WT group, two-tailed $t$ test. Chr chromosome. c Concentrations of cluster 1 and cluster 2 miR-200 s in human breast cancer samples at various tumor stages (tumor-node-metastasis (TNM) staging classifies cancers based on T1-T4, N, and M), as determined from data for 271 patients listed in the NCI The Cancer Genome Atlas (TCGA). Data are presented as the means \pm SD. ${ }^{*} p<0.05$ vs. T1-3 group, two-tailed $t$ test. $\mathbf{d}$ Plasma levels of miR-200c and miR-141 (determined by nest-qPCR) during tumor progression in Foxp $3^{\mathrm{sf} / \mathrm{t}}$ female mice. The time points of breast tumor development are indicated by vertical arrows (red arrows and blue arrows for metastatic and non-metastatic mice, respectively). Tumor progression was determined by the size and distant metastasis of tumors. The relative amounts were calculated using the $2^{-\Delta C t}$ against the cycle threshold (Ct) value at 1 year of age ${ }^{*} p<0.05$ vs. no tumor group; two-way analysis of variance). The time points of tumor development, assessed by visual observation, are indicated by vertical arrows. All experiments were repeated three times

patients with local breast cancer (42 with pT1-2N0M0 and 8 with pT3-4NOM0) and 25 patients with metastatic breast cancer (15 with only lymph node involvement (N1-3) after surgery, and 10 with distant metastatic disease (i.e., lungs, liver, bones) (M1) diagnosed after surgery). Also analyzed were 50 age-matched and ethnicitymatched healthy female controls. The $t$ tests confirmed significantly higher levels (lower adjusted Ct values) of plasma miR-200c and miR-141 in metastatic breast cancers compared to breast cancers localized to breast tissue only (miR-200c: 5.5 -fold, $p<0.001$; miR-141: 7.9fold, $p<0.001$ ) and controls (miR-200c: 7.8-fold, $p<0.001$;
miR-141: 18.4-fold, $p<0.001$ ) (Fig. 4b). There was no difference between localized breast cancers and controls, between tumor grades, or between ductal and lobular cancers (Fig. 4b and Additional file 1: Figure S7A-C).

To assess diagnostic potential, the sensitivity and specificity of plasma miR-200c and miR-141 were evaluated. ROC analysis predicted the capacity of plasma miR-200c and miR-141 to differentiate localized cases (Fig. 4c) from normal control cases or metastatic cases from localized cases (Fig. 4d). For localized cases versus controls, the area under curve (AUC) for plasma miR-200c and miR-141 was 0.557 (95\% confidence intervals: 0.441, 


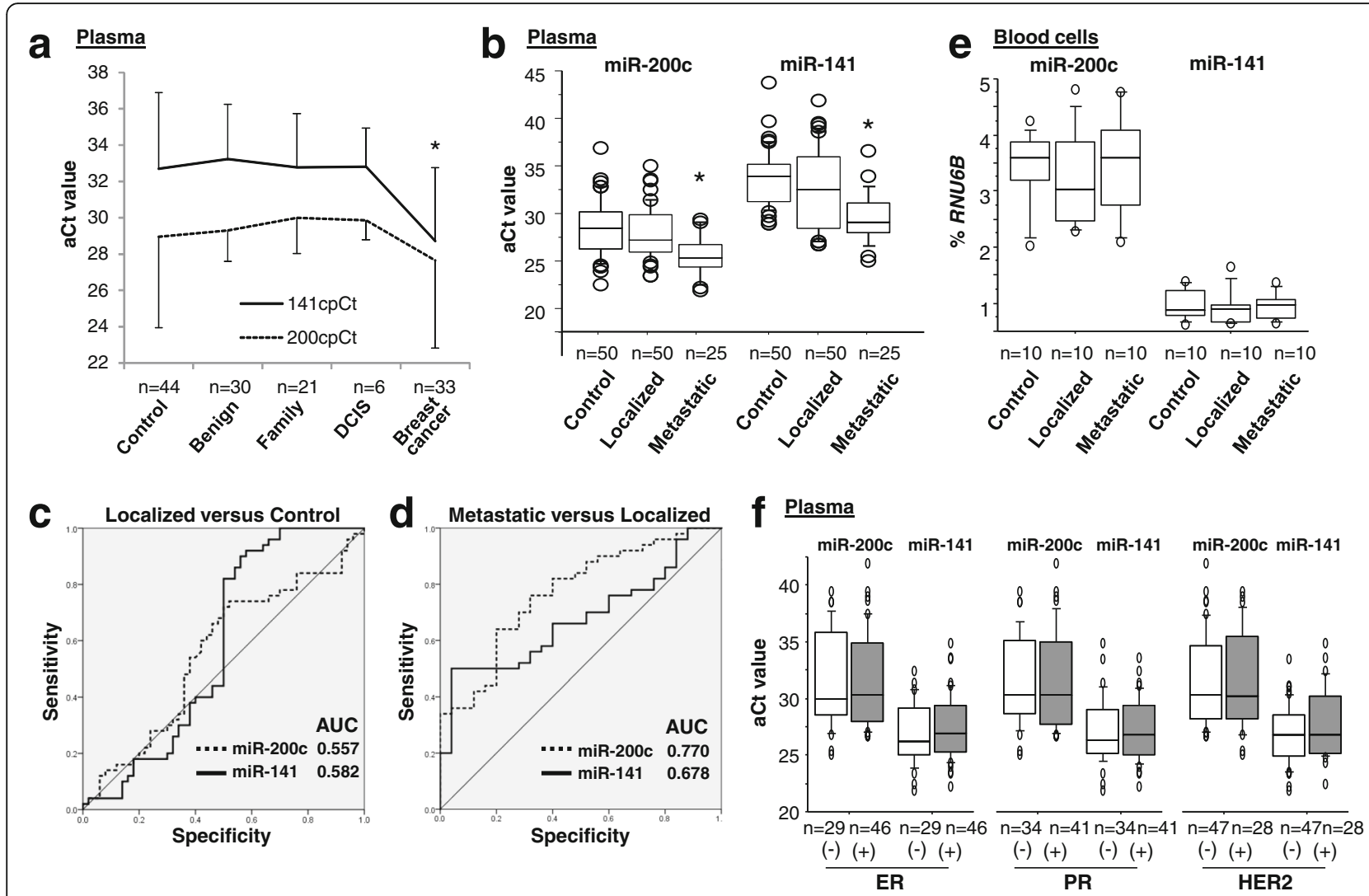

Fig. 4 Plasma levels of miR-200c and miR-141 are elevated in patients with metastatic breast cancer. a Plasma levels of miR-200c and miR-141 presented as adjusted PCR cycle threshold ( $a C t)$ values for normal female controls, patients with benign breast tumors, those with a family history of breast cancer, patients with breast ductal carcinoma in situ (DCIS), and patients with breast cancer. The aCt value of each miR was normalized to cel-miR-39 as described previously [4, 21]. In plasma levels of miR-141, ${ }^{*} p<0.05$ breast cancer vs. other groups (one-way analysis of variance (ANOVA) followed by the protected least significant difference test). b Plasma miR-200c and miR-141 levels represented as aCt values for patients with localized breast cancer, patients with metastatic breast cancer, and normal female controls. ${ }^{*} p<0.05$ disease vs. control group (one-way ANOVA followed by the protected least significant difference test). c, d Sensitivity and specificity of plasma miR-200c and miR-141 for patients with localized breast cancer relative to normal female controls and patients with metastatic breast cancer relative to patients with localized breast cancer. Receiver operating characteristic curves are shown for miR-200c (dotted line) and miR-141 (solid line). AUC area under the curve. e Llevels of miR-200c and miR-141 in blood cells presented as percentages of RUN6B expression for patients with localized breast cancer, patients with metastatic breast cancer, and normal female controls. f Plasma miR-200c and miR-141 levels presented as aCt values for breast cancer patients with estrogen receptor (ER), progesterone receptor (PR), and human epidermal growth factor receptor 2 (HER2) status. Data for all patients in this figure are not included in the The Cancer Genome Atlas datasets. All experiments were repeated three times

$0.672)$ and $0.582(0.463,0.702)$, respectively, but, for metastatic cases versus localized cases, the AUC for plasma miR-200c and miR-141 was higher at 0.770 $(0.661,0.880)$ and $0.678(0.558,0.799)$, respectively (Figs. 4c and d). These data reflect the patterns found in our mouse model (Fig. 3d). There were no significant differences between localized cases, metastatic cases, and controls in the levels of miR-200c and miR-141 in peripheral blood cells (Fig. 4e). Because hormonenegative breast cancers (ER/PR-negative) and HER2positive breast cancers are more likely to reoccur and spread outside the breast tissue compared to ER/PRpositive breast cancers [47], the effect of ER/PR/HER2 status on plasma levels of miR-200c and miR-141 was evaluated. There were no significant differences among the subgroups according to receptor status (Fig. 4f).

\section{During breast cancer metastasis, plasma levels of miR- 200c and miR-141 are likely derived from tumor cells}

Although, during breast cancer metastasis, there was differential expression of miR-200c and miR-141 in tumor cells (Figs. 3b and c) and plasma (Figs. 3d, 4a and b), whether miR-200c and miR-141 were released by tumor cells or blood cells [48] was not determined. To identify the source of plasma miR-200c and miR-141 and to characterize the transcriptional mechanisms regulating these molecules, an analysis of FOXP3/GFP Tet-off MCF7 cells was performed. After the removal of Dox, 
the levels of miR-200c and miR-141 in MCF7 cells, cell culture medium, and exosomes were measured before and after FOXP3 induction. At 0 to 5 days in culture without Dox, levels of miR-200c and miR-141 in tumor cells increased as FOXP3 was induced (Fig. 5a). Levels of extracellular miR-200c and miR-141 in the culture medium appeared to be increased, but there were intermittent increases and decreases (Fig. 5b). Levels of miR200c and miR-141 in exosomes increased with time after FOXP3 induction (Fig. 5c). There were, however, no significant differences in the amounts of miR-200b, miR200a, or miR-429 in MCF7 cells, cell culture medium, or exosomes (Additional file 1: Figure S8A-C). Since plasma miR-200c and miR-141 levels were elevated during tumor metastasis in Foxp $3^{\mathrm{s} /+}$ mice (Fig. 3d), the levels of miR-200 s in peripheral blood cells in Foxp $3^{\text {sf/+ }}$ mice at 21 months of age were measured. However, in peripheral blood cells, no significant changes in the miR-200 s levels were evident (Figs. 5d and Additional file 1: Figure S9). These data suggest that the elevated plasma levels of miR-200c and miR-141 in these mice are not derived from peripheral blood cells.
Exosomes are nano-sized $(50-150 \mathrm{~nm})$ membrane vesicles secreted by most cell types. Notably, tumor cells secrete more than threefold more exosomes than normal cells [49]. To determine if miR-200c and miR-141 levels were changed in exosomes present in the plasma of mice, plasma was prepared from the blood of Foxp $3^{\text {sf/+ }}$ mice at 2 years of age, and exosomes were extracted. Levels of exosomal miR-200c and miR-141 were higher (2.1/2.3-fold) in the mice with breast cancers, especially in those with tumor metastases (2.6/3.6fold), than in mice without breast cancer (Fig. 5e). On the other hand, expression levels of miR-200c and miR-141 in exosomes, but not cell-free and exosome-free culture medium, were reduced in the FOXP3-knockdown MCF10A cells (Additional file 1: Figure S1C-D).

\section{Discussion}

In the present study, we identified a FOXP3-KAT2BmiR-200c/141 transcriptional axis in breast cancer cells. However, the levels of miR-200c and miR-141 in tumor cells and in the circulation differed in mice, and differed in humans between patients with metastatic breast cancer, patients with localized breast cancer, and healthy

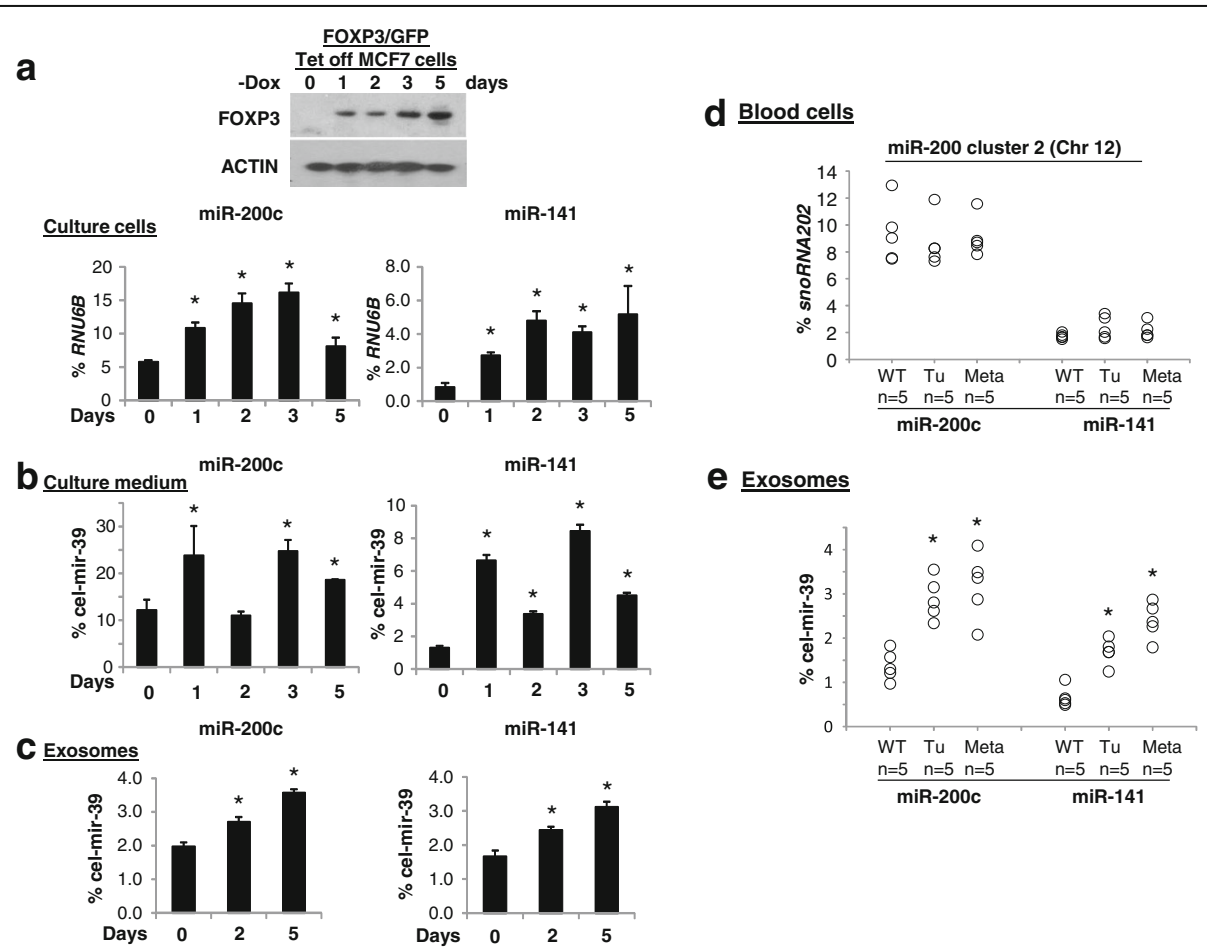

Fig. 5 Levels of tumor-derived exosomal miR-200c and miR-141 in breast cancer cells and animals. FOXP3 protein expression was measured by western blotting in FOXP3/GFP-Tet-off MCF7 cells. -Dox, doxycycline removed from the culture medium. a-c Quantification of miR-200c and miR-141 (by quantitative (q)PCR) as a percentage of RNU6B or cel-mir-39 expression in FOXP3/GFP-Tet-off MCF7 cells without Dox at 0, 1, 2, 3, and 5 days. Data are presented as means \pm SD. ${ }^{*} p<0.05$ vs. 0-h group (one-way analysis of variance (ANOVA) followed by the protected least significant difference test). d Levels of miR-200c and miR-141 in mouse blood cells (measured by qPCR) as a percentages of snoRNA202 expression. e Quantification of levels of exosomal miR-200c and miR-141 in mouse plasma (by QPCR) as percentages of cel-mir-39 expression. WT wild-type, Tu tumor, Meta metastasis. ${ }^{*} p<0.05$ vs. no tumor group (one-way ANOVA followed by the protected least significant difference test). All experiments were repeated three times 
female controls. The levels of miR-200c and miR-141 were low in primary tumor cells but were high in the circulation of patients with metastatic breast cancer. Further, our data suggested the cell origin of circulating miR-200c and miR-141 and their transcriptional regulation in cultured cells and during tumor progression in animal models of spontaneous breast cancer. Of note, miR-200c and miR-141 appeared to be released from breast cancer cells into the culture medium or into the circulation of mice during tumor progression.

Functional studies have found conflicting results on the role of miR-200 s in suppressing or promoting metastasis in different cellular contexts [11-14]. Likewise, early evidence showed increased expression levels of miR-200c and miR-141 in metastatic breast tumors [13], but recent studies revealed decreased expression of miR-200c in primary breast tumors with lymph node metastasis [50-52]. Our analysis of TCGA database identified downregulation of miR-200 s in primary breast cancer cells in patients with distant metastases. With the Foxp $3^{\text {sfl+ }}$ spontaneous breast cancer mouse model, we observed downregulation of miR-200c and miR-141 in primary breast cancer cells, especially in mice with lung metastases. Thus, these data suggest that FOXP3-induced miR-200c/141 may function as metastatic suppressors at primary sites [11, 12, 18, 19] but as metastatic promotors at metastatic sites $[13,14]$.

The clinical significance of circulating miR-200 $\mathrm{s}$ in patients with breast cancer has been investigated in a few recent studies. In patients with breast cancer, increased levels of circulating miR-200 s may be a predictor of CTCs [21], metastasis up to 2 years prior to clinical diagnosis [22], and poor survival [23]. In the present study, we found increased levels of plasma miR200c in patients with metastatic breast cancer who had no metastasis at diagnosis, as compared to those in patients with localized breast cancer. These findings are consistent with those observed during tumor metastasis in Foxp $3^{\mathrm{sf} /+}$ mice. Since plasma miR-200c and miR-141 increase prior to metastasis, they may serve as biomarkers for early detection of tumor metastasis, which is supported by results of recent studies [5, 21, 22]. However, in both humans and mice, we found that miR200c and miR-141 decrease in tumors but increase in the circulation, and are not changed in the blood cells. Of note, we also observed secretions of miR-200c and miR-141 in culture medium or in the circulation through exosomes in breast cancer cells and in animal models. Since expression levels of miR-200c and miR141 in blood cells are not changed in humans or mice, tumor cells are likely to be the source, but future studies are needed to address this complex mechanism of action.

During tumor progression, some miRs are released from blood cells [48]. Here, we measured the levels of
miR-200c and miR-141 in tumor cells, cell culture medium, and exosomes from FOXP3/GFP-Tet-off MCF7 cells. During FOXP3 induction, exosomal miR-200c and miR-141 were elevated, along with intracellular miR200c and miR-141. Although extracellular miR-200c and miR-141 were also increased in cell culture medium, this increase was not dependent on intracellular miR-200c and miR-141. Thus, exosomes may be transporters for releasing or secreting miR-200c and miR-141 from tumor cells. In $F o x p 3^{\text {sf } /+}$ mice, circulating miR-200c and miR-141 are unlikely to be released from blood cells. As circulating miR-200 s reflect the CTC status of patients with breast cancer [21], they may be released from CTCs through exosomes rather than from blood cells or primary tumor cells. In further studies, isolation of circulating CTCs and exosomes from mice or patients with breast cancer and comparison of expression levels of miR-200 s between CTCs and exosomes will address this hypothesis. A recent functional analysis revealed that extracellular vesicles containing miR-200c and miR-141 promote breast cancer cell metastasis through an enhanced MET transition [20]. This finding supports the idea that exosomal miR-200c and miR-141 are involved in metastasis of breast cancer and that they are biomarkers for early prediction of tumor metastasis.

Recent studies suggest that the miR-200c/141 cluster may act as a suppressor for the early stages of metastasis, but facilitate post-extravasation events, and that the miR-200b/a/429 cluster suppresses metastasis at all stages $[13,14,53]$. In addition, the promoter regions of the two clusters may be bound by different transcription factors. ZEB1 and ZEB2 both bind to the two miR-200 clusters, causing inhibition of the transcription of all miR-200 s; Sp1 binds the miR-200b/a/429 cluster [44, 54] and p53 binds the miR-200c/141 cluster [44, 55], leading to activation of transcription of miR200s. Likewise, direct binding of the KAT2B/P300/ZEB1 complex to the miR200c/141 promoter activates their transcription in cancer cells, but disruption of KAT2B and P300 interactions downregulates the promoter activity of miR200c/141, indicating a direct functional regulation of miR200c/141 by the KAT2B/P300/ZEB1 complex in cancer cells [39]. In the present study, FOXP3, through direct binding of KAT2B to the miR-200c/141 cluster, leads to activation of transcription of miR200c/141. These data suggest the presence of a FOXP3-KAT2BmiR200c/141 axis in breast cancer cells and a differential mechanism of transcriptional regulation between the two miR-200 clusters.

\section{Conclusions}

In breast cancer cells, miR-200c and miR-141 are regulated by a FOXP3-KAT2B axis, and circulating miR-200c and miR-141 are potential biomarkers for early detection 
of tumor metastasis. These observations will help in understanding how to predict metastasis of breast cancer and how to treat metastases.

\section{Additional files}

Additional file 1: Table S1. Primer and siRNA sequence used in this study. Figure S1. Levels of miR-200c and miR-141 in normal immortalized human epithelial cell line MCF10A. Figure S2. Associations between expression of FOXP3 and miR-200 s in TCGA breast cancer samples. Figure S3. Potential binding signals of FOXP3 in the promoter regions of the miR-200 family and KAT2B gene. Figure S4. The transcriptional activity of miR-200b/a/429 on miR-200 cluster 1 after FOXP3 induction and KAT2B silencing in breast cancer cells. Figure S5. Association of expression levels of miR-200 s with ER/PR/HER2 status in breast cancer cells. Figure S6. Levels of plasma miR-200b, 200a, and 429 in Foxp3sf/+ female mice during tumor progression. Figure S7. Plasma levels of miR-141 and 200c in breast cancer patients with clinical parameters. Figure S8. Levels of miR-200b, 200a, and 429 in FOXP3-Tet-off MCF7 cells, culture medium, and exosomes. Figure S9. Expression of miR-200b, 200a, and 429 in blood cells of Foxp3sf/t female mice. (DOCX $910 \mathrm{~kb}$ )

\section{Abbreviations}

aCt: Adjusted cycle threshold; ANOVA: Analysis of variance; AUC: Area under the curve; ChIP: Chromatin immunoprecipitation; CTCs: Circulating tumor cells; DCIS: Ductal carcinoma in situ; Dox: Doxycycline; EMT: Epithelial-mesenchymal transition; ER: Estrogen receptor; HER2: Human epidermal growth factor receptor 2; MET: Mesenchymal-epithelial transition; miR: MicroRNA; PBS: Phosphate-buffered saline; PR: Progesterone receptor; qPCR: Quantitative PCR; ROC: Receiver operating characteristic; Sf: Scurfy; siRNA: Small interfering RNA; TCGA: The Cancer Genome Atlas; TlL: Tumor-infiltrating lymphocyte; UAB: University of Alabama at Birmingham

\section{Acknowledgements}

We thank Dr. Donald L Hill and Mr. Raymond X. Wang for editorial assistance in preparing this manuscript.

\section{Funding}

This work was supported by the National Institutes of Health/National Cancer Institute (CA179282, CA199586, CA118948 and CA013148), National Institutes of Health/National Center for Advancing Translational Sciences (part of UL1TR001417), the Department of Defense (BC160808, PC130594 and PC140308), the UAB Pittman Scholar Award, the Larsen Endowment Fellowship program Grant, the Rubye Smith Trust Fund, and the Mercer University Seed Grant.

\section{Availability of data and materials}

All available datasets are presented herein

\section{Authors' contributions}

$L W, R L$, and $R C$ designed all experiments. GZ, BL, LS, WHY, KJ, and WZ performed the in vitro experiments. CC, RL, GZ, SW, and WZ performed the in vivo experiments. DC, SB, and ESR performed the data analysis. GZ, WZ, $E S R, L W$, and RL assisted in collecting specimens from human subjects. LW, $\mathrm{RL}, \mathrm{RC}$, and ESR wrote, edited, and proofread the manuscript. All authors read and approved the final manuscript.

\section{Competing interests}

The authors declare that they have no competing interests.

\section{Consent for publication}

No individual level data are presented in this manuscript.

\section{Ethics approval and consent to participate}

The present study, with human subjects, was approved by the Ethics Committee of UAB. For all human specimens, informed consent was obtained from all subjects in accordance with the requirements of the Institutional Review Board of UAB. All animal studies were approved by the Institutional Animal Care and Use Committee of UAB.

\section{Publisher's Note}

Springer Nature remains neutral with regard to jurisdictional claims in published maps and institutional affiliations.

\section{Author details}

${ }^{1}$ Provincial Key Laboratory on Molecular and Chemical Genetic, The Second Hospital of Jilin University, Changchun 130041, People's Republic of China. 2Department of Genetics, University of Alabama at Birmingham, Birmingham, AL 35294, USA. ${ }^{3}$ Chinese Center for Endemic Disease Control, Harbin Medical University, Harbin 150081, People's Republic of China. ${ }^{4}$ Hematology/ Oncology Section, Department of Medicine, University of Alabama at Birmingham, Birmingham, AL 35294, USA. ${ }^{5}$ Department of Applied Psychology, Humanities and Management Colleges, Guangdong Medical University, Dongguan 523808, People's Republic of China. ${ }^{6}$ Division of Preventive Medicine, University of Alabama at Birmingham, Birmingham, AL 35294, USA. 'Department of Pathology, University of Alabama at Birmingham, Birmingham, AL 35294, USA. ${ }^{8}$ Comprehensive Cancer Center, University of Alabama at Birmingham, Birmingham, AL 35294, USA.

${ }^{9}$ Department of Biomedical Sciences, Mercer University, Savannah, GA 31404, USA.

Received: 30 January 2017 Accepted: 17 May 2017

Published online: 21 June 2017

\section{References}

1. Siegel RL, Miller KD, Jemal A. Cancer facts \& figures 2015, vol. 65. Atlanta: American Cancer Society; 2015. p. 5-29.

2. Weigelt $B$, Peterse $J \mathrm{~L}$, van 't Veer $L J$. Breast cancer metastasis: markers and models. Nat Rev Cancer. 2005;5(8):591-602.

3. Lu J, Getz G, Miska EA, Alvarez-Saavedra E, Lamb J, Peck D, Sweet-Cordero A, Ebert BL, Mak RH, Ferrando AA, et al. MicroRNA expression profiles classify human cancers. Nature. 2005;435(7043):834-8.

4. Mitchell PS, Parkin RK, Kroh EM, Fritz BR, Wyman SK, Pogosova-Agadjanyan EL, Peterson A, Noteboom J, O'Briant KC, Allen A, et al. Circulating microRNAs as stable blood-based markers for cancer detection. Proc Natl Acad Sci U S A. 2008;105(30):10513-8.

5. Roth C, Rack B, Muller V, Janni W, Pantel K, Schwarzenbach H. Circulating microRNAs as blood-based markers for patients with primary and metastatic breast cancer. Breast Cancer Res. 2010;12(6):R90.

6. Pigati L, Yaddanapudi SC, lyengar R, Kim DJ, Hearn SA, Danforth D, Hastings ML, Duelli DM. Selective release of microRNA species from normal and malignant mammary epithelial cells. PLoS One. 2010;5(10):e13515.

7. Zhao H, Shen J, Medico L, Wang D, Ambrosone CB, Liu S. A pilot study of circulating miRNAs as potential biomarkers of early stage breast cancer. PLoS One. 2010;5(10):e13735.

8. Wu X, Somlo G, Yu Y, Palomares MR, Li AX, Zhou W, Chow A, Yen Y, Rossi $J$ J, Gao $H$, et al. De novo sequencing of circulating miRNAs identifies novel markers predicting clinical outcome of locally advanced breast cancer. J Transl Med. 2012;10:42.

9. van Schooneveld E, Wouters MC, Van der Auwera I, Peeters DJ, Wildiers $\mathrm{H}_{\text {, }}$ Van Dam PA, Vergote I, Vermeulen PB, Dirix LY, Van Laere SJ. Expression profiling of cancerous and normal breast tissues identifies microRNAs that are differentially expressed in serum from patients with (metastatic) breast cancer and healthy volunteers. Breast Cancer Res. 2012;14(1):R34.

10. Schrauder MG, Strick R, Schulz-Wendtland R, Strissel PL, Kahmann L, Loehberg CR, Lux MP, Jud SM, Hartmann A, Hein A, et al. Circulating microRNAs as potential blood-based markers for early stage breast cancer detection. PLoS One. 2012;7(1):e29770.

11. Gregory PA, Bert AG, Paterson EL, Barry SC, Tsykin A, Farshid G, Vadas MA, Khew-Goodall Y, Goodall GJ. The miR-200 family and miR-205 regulate epithelial to mesenchymal transition by targeting ZEB1 and SIP1. Nat Cell Biol. 2008;10(5):593-601.

12. Korpal M, Lee ES, Hu G, Kang Y. The miR-200 family inhibits epithelialmesenchymal transition and cancer cell migration by direct targeting of $\mathrm{E}-$ cadherin transcriptional repressors ZEB1 and ZEB2. J Biol Chem. 2008; 283(22):14910-4.

13. Korpal M, Ell BJ, Buffa FM, Ibrahim T, Blanco MA, Celia-Terrassa T, Mercatali L Khan Z, Goodarzi H, Hua Y, et al. Direct targeting of Sec23a by miR-200 s influences cancer cell secretome and promotes metastatic colonization. Nat Med. 2011;17(9):1101-8. 
14. Dykxhoorn DM, Wu Y, Xie H, Yu F, Lal A, Petrocca F, Martinvalet D, Song E, Lim B, Lieberman J. miR-200 enhances mouse breast cancer cell colonization to form distant metastases. PLoS One. 2009;4:e7181.

15. Bracken CP, Khew-Goodall Y, Goodall GJ. Network-based approaches to understand the roles of miR-200 and other microRNAs in cancer. Cancer Res. 2015;75(13):2594-9.

16. Li X, Roslan S, Johnstone CN, Wright JA, Bracken CP, Anderson M, Bert AG, Selth LA, Anderson RL, Goodall GJ, et al. MiR-200 can repress breast cancer metastasis through ZEB1-independent but moesin-dependent pathways. Oncogene. 2014;33(31):4077-88.

17. Howe EN, Cochrane DR, Richer JK. Targets of miR-200c mediate suppression of cell motility and anoikis resistance. Breast Cancer Res. 2011;13(2):R45.

18. Ahmad A, Aboukameel A, Kong D, Wang Z, Sethi S, Chen W, Sarkar FH, Raz A. Phosphoglucose isomerase/autocrine motility factor mediates epithelialmesenchymal transition regulated by miR-200 in breast cancer cells. Cancer Res. 2011;71(9):3400-9.

19. Knezevic J, Pfefferle AD, Petrovic I, Greene SB, Perou CM, Rosen JM. Expression of miR-200c in claudin-low breast cancer alters stem cell functionality, enhances chemosensitivity and reduces metastatic potential. Oncogene. 2015:34(49):5997-6006.

20. Le MT, Hamar P, Guo C, Basar E, Perdigao-Henriques R, Balaj L, Lieberman J. miR-200-containing extracellular vesicles promote breast cancer cell metastasis. J Clin Invest. 2014;124(12):5109-28.

21. Madhavan D, Zucknick M, Wallwiener M, Cuk K, Modugno C, Scharpff M, Schott S, Heil J, Turchinovich A, Yang R, et al. Circulating miRNAs as surrogate markers for circulating tumor cells and prognostic markers in metastatic breast cancer. Clin Cancer Res. 2012;18(21):5972-82.

22. Madhavan D, Peng C, Wallwiener M, Zucknick M, Nees J, Schott S, Rudolph A, Riethdorf S, Trumpp A, Pantel K, et al. Circulating miRNAs with prognostic value in metastatic breast cancer and for early detection of metastasis. Carcinogenesis. 2016;37(5):461-70.

23. Debeb BG, Lacerda L, Anfossi S, Diagaradjane P, Chu K, Bambhroliya A, Huo L, Wei C, Larson RA, Wolfe AR, et al. miR-141-mediated regulation of brain metastasis from breast cancer. J Natl Cancer Inst. 2016;108:8.

24. Hori S, Nomura T, Sakaguchi S. Control of regulatory T cell development by the transcription factor Foxp3. Science. 2003;299(5609):1057-61.

25. Liu R, Wang L, Chen G, Katoh H, Chen C, Liu Y, Zheng P. FOXP3 upregulates p21 expression by site-specific inhibition of histone deacetylase 2/ histone deacetylase 4 association to the locus. Cancer Res. 2009;69(6):2252-9.

26. Zuo T, Wang L, Morrison C, Chang X, Zhang H, Li W, Liu Y, Wang Y, Liu X, Chan MW, et al. FOXP3 is an X-linked breast cancer suppressor gene and an important repressor of the HER-2/ErbB2 oncogene. Cell. 2007;129(7):1275-86.

27. Zuo T, Liu R, Zhang H, Chang X, Liu Y, Wang L, Zheng P, Liu Y. FOXP3 is a novel transcriptional repressor for the breast cancer oncogene SKP2. J Clin Invest. 2007;117(12):3765-73.

28. Ladoire S, Arnould L, Mignot G, Coudert B, Rebe C, Chalmin F, Vincent J, Bruchard M, Chauffert B, Martin F, et al. Presence of Foxp3 expression in tumor cells predicts better survival in HER2-overexpressing breast cancer patients treated with neoadjuvant chemotherapy. Breast Cancer Res Treat. 2011;125(1):65-72.

29. Ladoire S, Mignot G, Dalban C, Chevriaux A, Arnould L, Rebe C, Apetoh L, Boidot R, Penault-Llorca F, Fumoleau P, et al. FOXP3 expression in cancer cells and anthracyclines efficacy in patients with primary breast cancer treated with adjuvant chemotherapy in the phase III UNICANCER-PACS 01 trial. Ann Oncol. 2012;23(10):2552-61.

30. Katoh H, Qin ZS, Liu R, Wang L, Li W, Li X, Wu L, Du Z, Lyons R, Liu CG, et al. FOXP3 orchestrates H4K16 acetylation and H3K4 trimethylation for activation of multiple genes by recruiting MOF and causing displacement of PLU-1. Mol Cell. 2011;44(5):770-84.

31. Liu R, Liu C, Chen D, Yang WH, Liu X, Liu CG, Dugas CM, Tang F, Zheng P, Liu Y, et al. FOXP3 controls an miR-146/NF-kappaB negative feedback loop that inhibits apoptosis in breast cancer cells. Cancer Res. 2015;75(8):1703-13.

32. Wang K, Yuan Y, Cho JH, McClarty S, Baxter D, Galas DJ. Comparing the microRNA spectrum between serum and plasma. PLoS One. 2012;7(7):e41561.

33. Liu R, Yi B, Wei S, Yang WH, Hart KM, Chauhan P, Zhang W, Mao X, Liu X, Liu CG, et al. FOXP3-miR-146-NF-kappaB axis and therapy for precancerous lesions in prostate. Cancer Res. 2015;75(8):1714-24.

34. Thery C, Amigorena S, Raposo G, Clayton A. Isolation and characterization of exosomes from cell culture supernatants and biological fluids. Curr Protoc Cell Biol. 2006;3(Unit 3):22.
35. Gallo A, Tandon M, Alevizos I, Illei GG. The majority of microRNAs detectable in serum and saliva is concentrated in exosomes. PLoS One. 2012;7(3):e30679.

36. Ma GF, Miao Q, Liu YM, Gao H, Lian JJ, Wang YN, Zeng XQ, Luo TC, Ma LL, Shen ZB, et al. High FoxP3 expression in tumour cells predicts better survival in gastric cancer and its role in tumour microenvironment. $\mathrm{Br}$ J Cancer. 2014;110(6):1552-60.

37. Chen GY, Chen C, Wang L, Chang X, Zheng P, Liu Y. Cutting edge: Broad expression of the FoxP3 locus in epithelial cells: a caution against early interpretation of fatal inflammatory diseases following in vivo depletion of FoxP3-expressing cells. J Immunol. 2008;180(8):5163-6.

38. Tian Y, Pan Q, Shang Y, Zhu R, Ye J, Liu Y, Zhong X, Li S, He Y, Chen L, et al. MicroRNA-200 (miR-200) cluster regulation by achaete scute-like 2 (Ascl2): impact on the epithelial-mesenchymal transition in colon cancer cells. J Biol Chem. 2014;289(52):36101-15.

39. Mizuguchi Y, Specht S, Lunz 3rd JG, Isse K, Corbitt N, Takizawa T, Demetris AJ. Cooperation of p300 and PCAF in the control of microRNA 200c/141 transcription and epithelial characteristics. PLoS One. 2012;7(2):e32449.

40. Zhang B, Zhang Z, Xia S, Xing C, Ci X, Li X, Zhao R, Tian S, Ma G, Zhu Z, et al. KLF5 activates microRNA 200 transcription to maintain epithelial characteristics and prevent induced epithelial-mesenchymal transition in epithelial cells. Mol Cell Biol. 2013;33(24):4919-35.

41. Mohr AM, Bailey JM, Lewallen ME, Liu X, Radhakrishnan P, Yu F, Tapprich W, Hollingsworth MA. MUC1 regulates expression of multiple microRNAs involved in pancreatic tumor progression, including the miR-200c/141 cluster. PLoS One. 2013;8(10):e73306.

42. Cao H, Jheon A, Li X, Sun Z, Wang J, Florez S, Zhang Z, McManus MT, Klein OD, Amendt BA. The Pitx2:miR-200c/141:noggin pathway regulates Bmp signaling and ameloblast differentiation. Development. 2013;140(16):3348-59.

43. Gregory PA, Bracken CP, Smith E, Bert AG, Wright JA, Roslan S, Morris M, Wyatt L, Farshid G, Lim YY, et al. An autocrine TGF-beta/ZEB/miR-200 signaling network regulates establishment and maintenance of epithelialmesenchymal transition. Mol Biol Cell. 2011;22(10):1686-98.

44. Kim T, Veronese A, Pichiorri F, Lee TJ, Jeon YJ, Volinia S, Pineau P, Marchio A, Palatini J, Suh SS, et al. p53 regulates epithelial-mesenchymal transition through microRNAs targeting ZEB1 and ZEB2. J Exp Med. 2011;208(5):875-83.

45. Burk U, Schubert J, Wellner U, Schmalhofer O, Vincan E, Spaderna S, Brabletz T. A reciprocal repression between $Z E B 1$ and members of the miR-200 family promotes EMT and invasion in cancer cells. EMBO Rep. 2008;9(6):582-9.

46. Mar-Aguilar F, Mendoza-Ramirez JA, Malagon-Santiago I, Espino-Silva PK, Santuario-Facio SK, Ruiz-Flores P, Rodriguez-Padilla C, Resendez-Perez D. Serum circulating microRNA profiling for identification of potential breast cancer biomarkers. Dis Markers. 2013:34(3):163-9.

47. Elias AD. Triple-negative breast cancer: a short review. Am J Clin Oncol. 2010;33(6):637-45

48. Pritchard CC, Kroh E, Wood B, Arroyo JD, Dougherty KJ, Miyaji MM, Tait JF, Tewari M. Blood cell origin of circulating microRNAs: a cautionary note for cancer biomarker studies. Cancer Prev Res (Phila). 2012;5(3):492-7.

49. Taylor DD, Gercel-Taylor C. MicroRNA signatures of tumor-derived exosomes as diagnostic biomarkers of ovarian cancer. Gynecol Oncol. 2008;110(1):13-21.

50. Berber U, Yilmaz I, Narli G, Haholu A, Kucukodaci Z, Demirel D. miR-205 and miR-200c: predictive micro RNAs for lymph node metastasis in triple negative breast cancer. J Breast Cancer. 2014;17(2):143-8.

51. Xu F, He H, Huang W, Lin Y, Luo S, Du Q, Duan R. Decreased expression of MicroRNA-200 family in human breast cancer is associated with lymph node metastasis. Clin Transl Oncol. 2016;18(3):283-8.

52. Damiano V, Brisotto G, Borgna S, di Gennaro A, Armellin M, Perin T, Guardascione M, Maestro R, Santarosa M. Epigenetic silencing of miR-200c in breast cancer is associated with aggressiveness and is modulated by ZEB1. Genes Chromosomes Cancer. 2017;56(2):147-58.

53. Humphries B, Yang C. The microRNA-200 family: small molecules with novel roles in cancer development, progression and therapy. Oncotarget. 2015;6(9):6472-98.

54. Kolesnikoff N, Attema JL, Roslan S, Bert AG, Schwarz QP, Gregory PA, Goodall GJ. Specificity protein 1 (Sp1) maintains basal epithelial expression of the miR-200 family: implications for epithelial-mesenchymal transition. J Biol Chem. 2014;289(16):11194-205.

55. Chang CJ, Chao CH, Xia W, Yang JY, Xiong Y, Li CW, Yu WH, Rehman SK, Hsu $\mathrm{L}$, Lee $\mathrm{HH}$, et al. p53 regulates epithelial-mesenchymal transition and stem cell properties through modulating miRNAs. Nat Cell Biol. 2011;13(3):317-23. 